\title{
Participation in and access to the defence heritage: some Swedish examples
}

\author{
A. Bodin \\ National Property Board, Sweden
}

\begin{abstract}
Increased public participation is absolutely vital in the field of fortifications and defence heritage. The defence heritage must be managed in interaction with its connections and contexts much more than today. The defence heritage is an important part of architectural history, history and politics, technology development and, not least, everyday life and mentality. To put it simply: the defence heritage is a part of the country's general culture and must therefore be managed as an integral part of that general culture. This paper will try to show how Sweden is working to achieve this goal. It will also give a brief survey of the special Swedish background, such as a tradition of centralized and coordinated governmental bodies. In Sweden, defence monuments from medieval times to the Cold War era are managed by the same governmental body that manages the general state-owned architectural heritage - National Property Board Sweden. The paper will list concrete activities that have promoted participation and accessibility in the realm of defence heritage. The Secret Places project will be analysed more deeply. The survey will conclude with a future dream project: a cooperation across the Baltic Sea that links a former Soviet nuclear missile silo in Lithuania with a Swedish underground gun battery.

Keywords: defence heritage, participation, Sweden, architectural history, cold war, cultural management, museums, guides, mutual information.
\end{abstract}

\section{Context}

The history of defence is intertwined with the general history of culture and societies. It is not hard to see that the thinking, the investments and the results from war and defence preparations constitute one of the most forceful powers for change in industry, inventions, production, mentalities and everyday life. The 
closer we come to our own time, the more intertwined the two fields are: ISO 9000, Google maps and yes, the entire Internet, are all spin-offs from the defence industry.

If we turn to the way the history of architecture and construction treats these facts, the situation is more ambivalent. In a history of general medieval architecture, fortifications, and their functions, have an established place. But the closer we come to our own era, the more the connections and dependences are lacking.

There are many reasons for this. One is of course a thoughtless presumption, very clearly put by a former Swedish minister of culture: "Well, war is the opposite of culture, isn't it?" Another explanation is that many fortification historians have surrounded themselves with an arsenal of terms that are excluding: redoubts, revelins and calibres, and so on. A third explanation can be found in the separated organizational systems. Since the $16^{\text {th }}$ century, Sweden has had two governmental bodies for planning, construction and management of public buildings: one for military buildings and one for civilian. If we are to come to terms with this split situation, we must explore many different ways to cooperate.

\section{The Swedish systems}

Twenty years ago, there were over a hundred small local museums preserving and displaying what we a little sarcastically might call military leftovers. They received funding from the military budget to varying degrees, but in times of cutbacks many of them also asked for support from the cultural budget. To be able to handle all these applications, the government made a survey and decided to support twenty-five of them more substantially if they agreed to devote themselves to only one priority field so that the total breadth of Swedish defence could thereby be handled and told. The museums were to be connected in a network run by professional curators. This network is called Swedish Military Heritage and is now operational. They were given a website addressing the general public in Swedish, English, Russian, Finnish and German [1].

The governmental body for the planning, construction and maintenance of the fortifications in use is the Swedish Fortifications Agency. Until 1993, part of their mission was also to manage historic buildings that had been used by the military. But it was then decided to transfer these buildings to the governmental organization for state-owned public buildings - the National Property Board. Most of them were bastion fortifications from the $17^{\text {th }}$ century, for example the Varberg, Carlsten and Landskrona fortresses. One might say that a 300-year-old tradition of defining buildings by their use, or former use, was thus abandoned in favour of a definition referring to their status as general cultural heritage.

The most important part of the 1993 deal was however the decision that all fortifications that were no longer to have any military use were to be turned over to the National Property Board if the antiquarian authorities considered them to be of such an importance that the board wanted them protected [2]. This arrangement weighed heavily when the radical decision was made in 1999 to shut down and abandon all of Sweden's fixed artillery batteries, many of them built as late as in 
the 1980s. The most valuable according to type, function and situation were, or are to be, transferred to the National Property Board. So this is the reason why the whole chronological sequence of Swedish fortifications from medieval times to the Cold War era is now managed by the same hand that also manages Sweden's state-owned civilian heritage.

Before I describe in a little more detail how these special buildings can be used to broaden participation and access as regards the Defence Heritage, I would like to say a word or two about another small but important step towards a wider perspective of our defence heritage. Through a private initiative, three guide-books on Sweden's architectural heritage were recently published. Two are on culturally well-established subjects, palaces and churches, but the third is about fortifications, from the Iron Age to the Cold War [3]. As parts of the same series, all three have the same structure and layout. The books are intended to go together and they clearly state that everything is part of our cultural heritage. I am perhaps over-interpreting this event, but the editor of the books is very outspoken: "I want to reclaim the defence heritage from the fortification nerds and place it in the middle of our general cultural history".

\section{Historic fortifications in one hand}

The whole array of Swedish fortifications - from the medieval high-raised fortified castles like Bohus; bastioned forts, like Carlsten; late $20^{\text {th }}$ century underground forts, like Boden; to the modern deep underground forts, like Landsort - can be maintained and described for the public as parts of one historic development (figs 1 and 2). And what is perhaps more important is that they can be described in the context of related civilian monuments. The connections to politics, technical development, architecture and everyday life will be easier to extract. It is possible to be coherent and balanced in information materials and public relations.

For all listed objects, the National Property Board draws up a conservation and development programme. It is a roughly 200 page document where most pages describe an object's history and present state. But the most demanding parts to draw up are the very condensed chapters called Value and Goal. These chapters must answer the questions: What is the importance of this? What can it tell us? How shall it be maintained to be able to tell us this also in the future? The same questions are to be answered for a royal palace and for a Cold War bunker!

\section{Secret Places}

In 2012, the National Property Board decided to initiate a special project to increase knowledge and understanding of Sweden's defence heritage. The project was called Secret Places and the theme was the balance of power. The idea was to open up places that are generally never open to the public. They are too dangerous to open up without special security measures. Fifteen were selected in order to give a broad regional and historic picture. The event was carefully marketed with press conferences and advertisements in newspapers and on television. Secret 


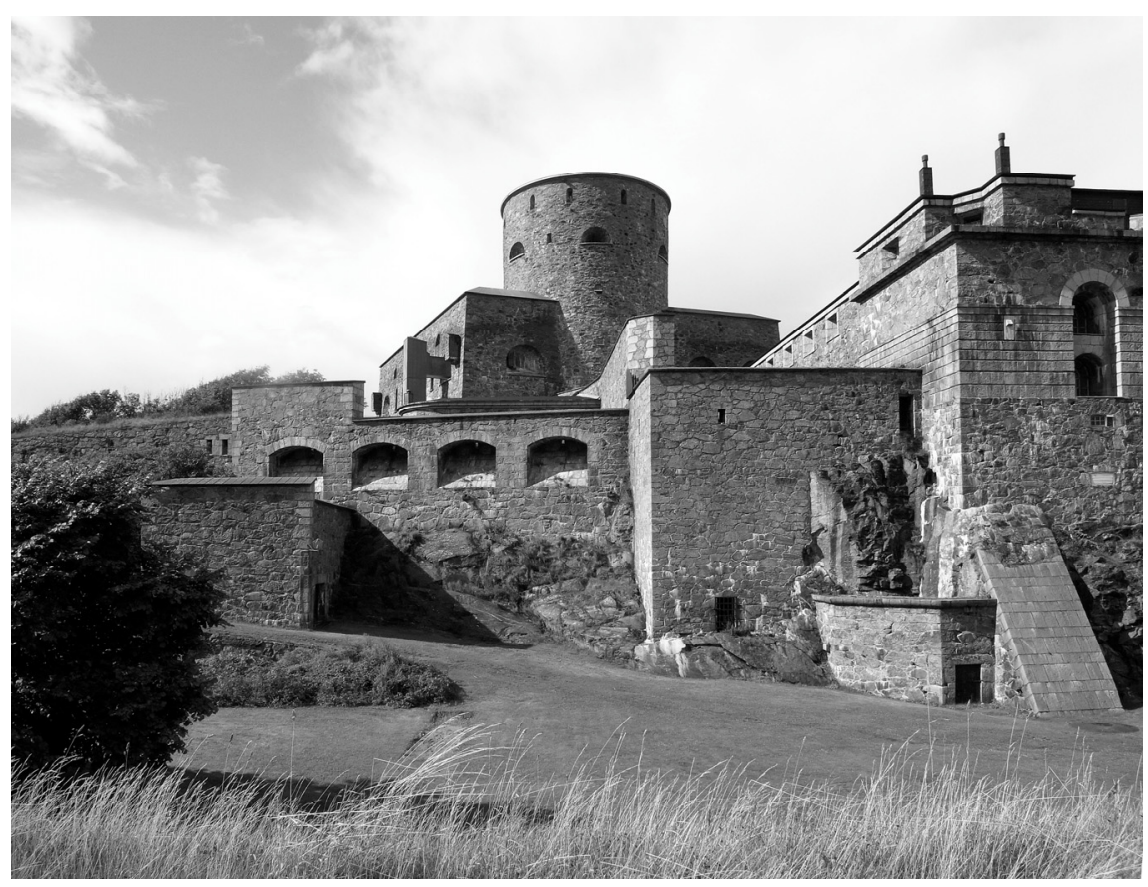

Figure 1: Carlstens fästning, Marstrand, Sweden $-17^{\text {th }}$ century.

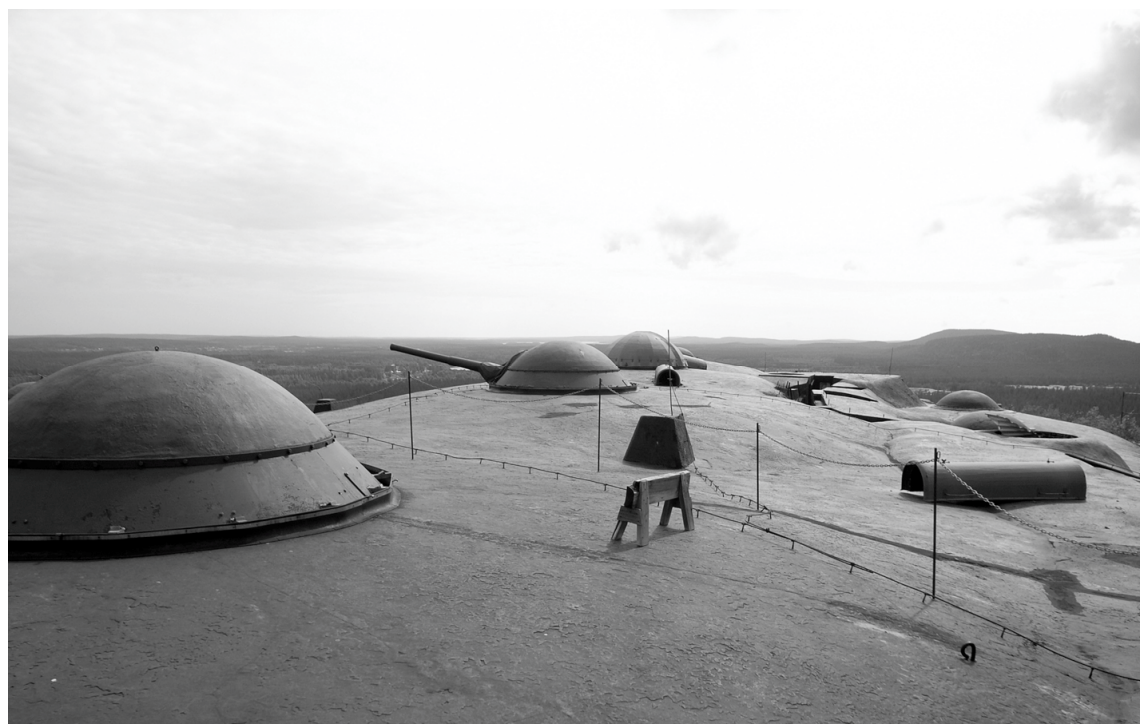

Figure 2: Bodens fästning, Boden, Sweden, 1905. 
Places had its own website and was promoted in social media. A short and very dramatic trailer was made with the message: One day! Do you dare? It's yours!

Among the sites was one of the seven underground fortresses from 1907 that surround the city of Boden: Södra Åberget, never before shown to the public. Another was the underground gun battery from the 1970s in Landsort in the Stockholm archipelago and which was top secret until 2007.

The Secret Places project was a success, with 45,000 visitors on the day and extensive media coverage before and after. The spectacular event also attracted new target groups: $25 \%$ of the visitors brought their children and almost $40 \%$ were women (figs 3 and 4). These are not the traditional figures for historic defence sites. For the visitor, the event, with its dramatic highlights, is probably something they will never forget. But more important are perhaps the surrounding activities and the more general information about this "other world", its enormous costs and its political context.

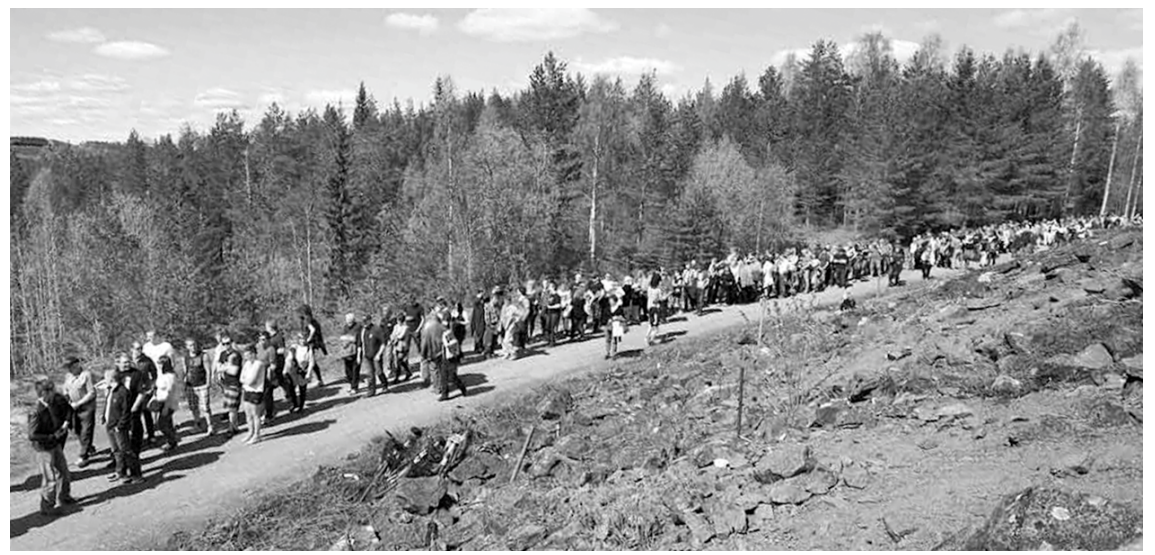

Figure 3: Queue for a Secret Place.

\section{Future dream project}

One of the Secret Places, the underground gun battery from the 1970s in Landsort is a five-storey steel construction hidden deep in the rock with only the gun and a horizontal door visible on the ground. Complete with full board for 30 soldiers, it had the capacity to fire 25 projectiles a minute and was both nuclear safe and electromagnetic pulse proof (fig. 5).

When we began our research for the information material for Secret Places, we soon found that it was impossible to understand the full extent of this very costly advanced machinery without speaking about the threats. What led Sweden to spend these millions and millions? I went to Lithuania. In Plunge, 25 kilometres from the Baltic coast, I visited one of the eight registered Soviet mid-range nuclear missile silos in operation up to 1991 (fig. 6). At the time of my visit, it was very hard to find: definitely not on any map and no signs but unlocked for me by the local folk museum. 


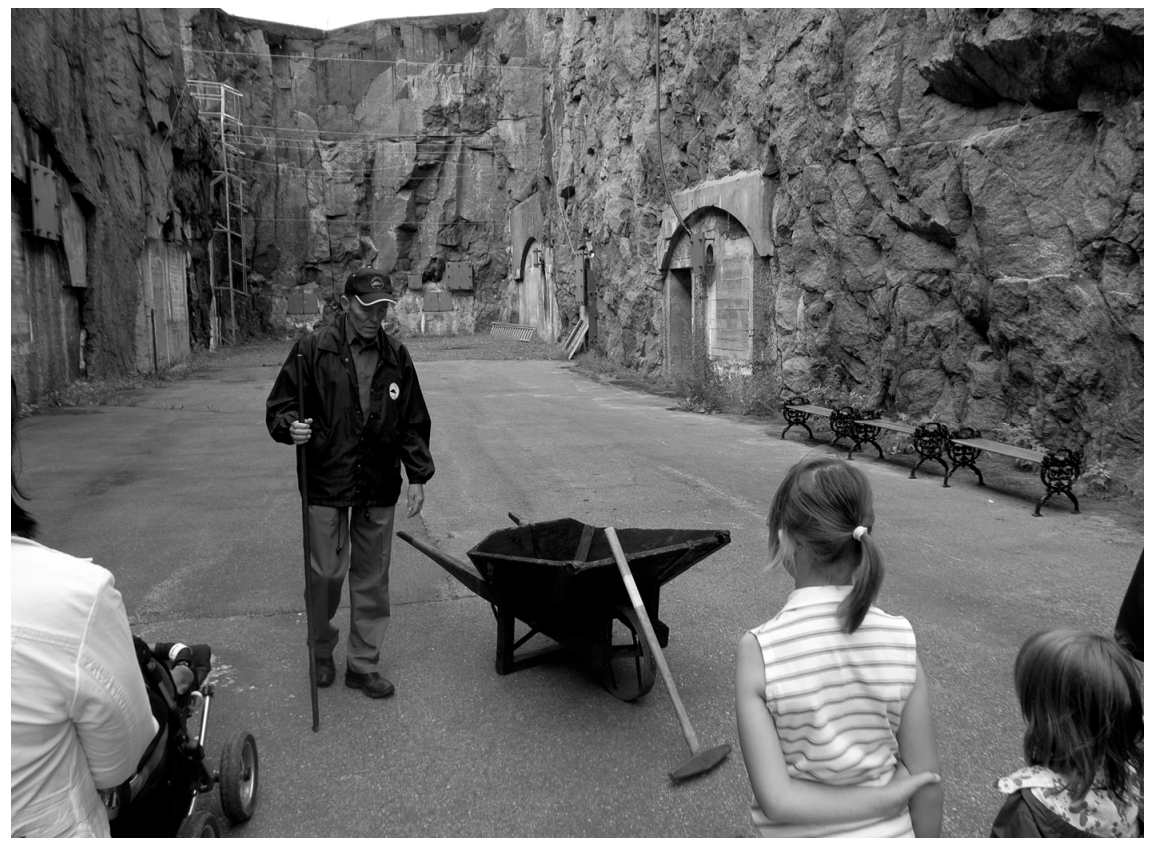

Figure 4: The former commandant of Bodens fästning explains how it was built.

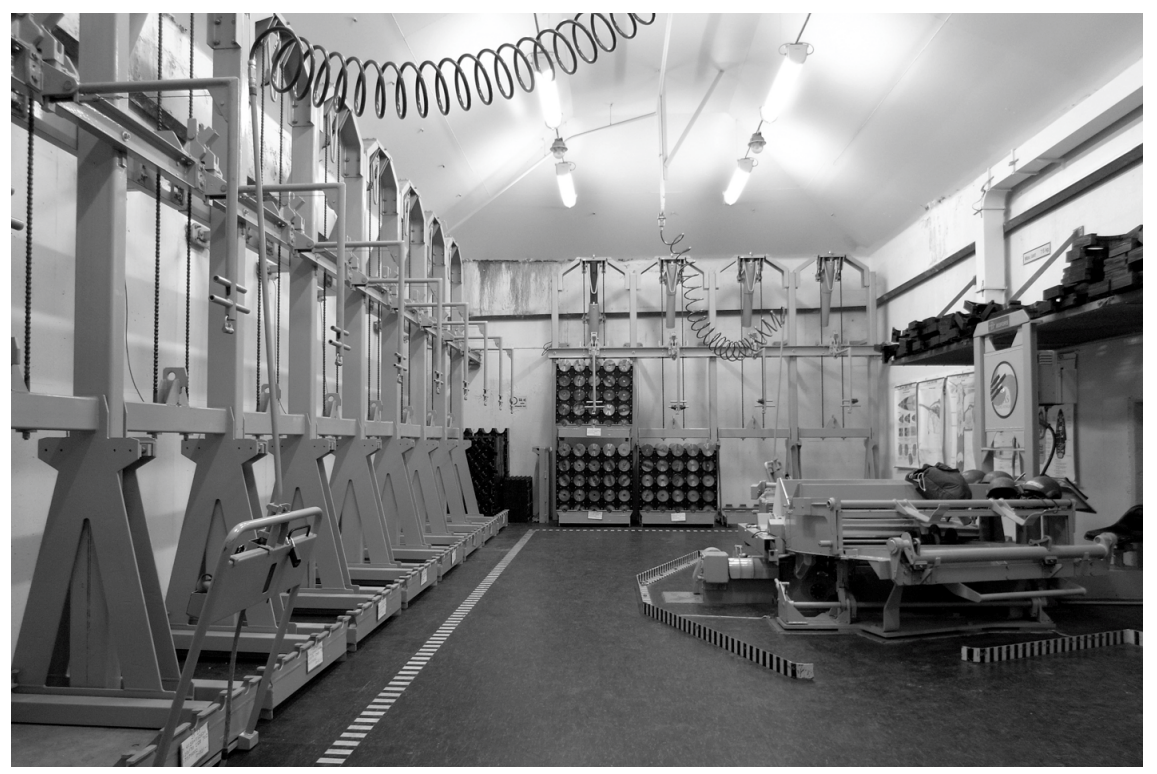

Figure 5: Underground gun battery from the 1970s in Landsort, Sweden. 


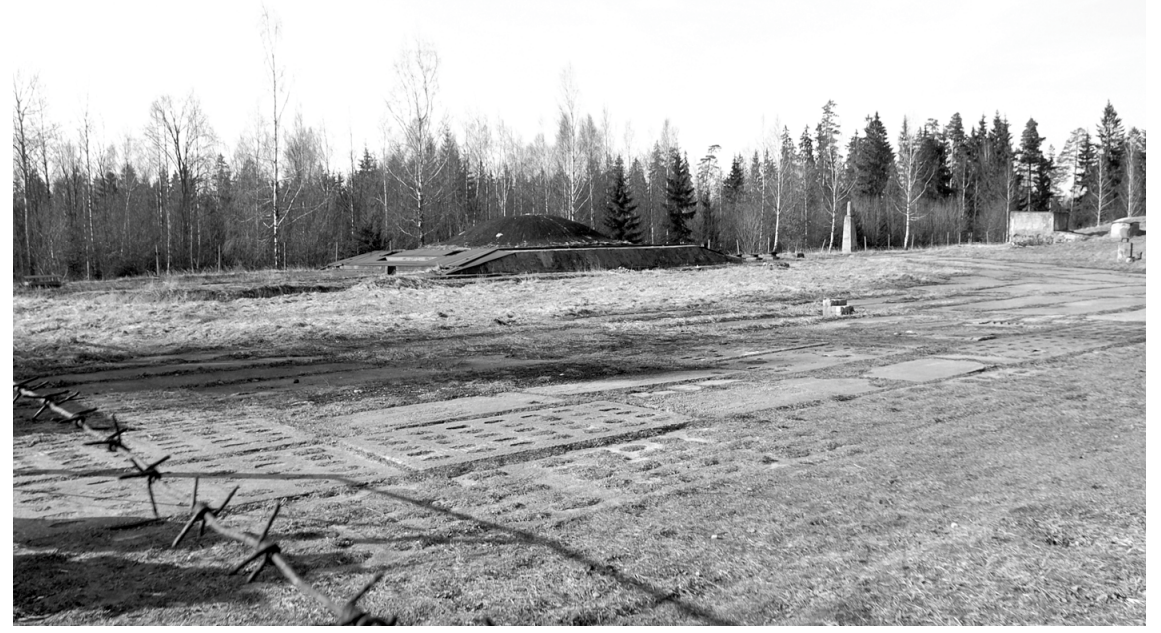

Figure 6: Underground Soviet nuclear missile silos in operation up to 1991, Plokstine, Plunge, Lithuania.

A concept for a future cooperation project began to take shape: we ought to talk about the Cold War period with one tongue. We ought to link Plunge with Landsort. Exactly the same information, including a political interpretation, will be given on both sites, thus creating a bridge of mutual understanding for the way the balance of terror held us in its grip of fear.

\section{End of an era}

It is not often in the history of architecture that it is possible to say that one era is definitely over. Satellite navigation and guided missiles have forever made fixed place-bound fortifications obsolete. From the Swedish horizon, at least two thousand years of fortification history are over. From the first structurally supported natural rocks of the Iron Age, to the medieval fortified towers, to the intricate bastion systems of the renaissance, to the industrial era's rock-covered machinery.

The future will be mobile, unpredictable, unseen and under-covered.

\section{References}

[1] Swedish Military Heritage. www.sfhm.se/smha

[2] National Property Board Sweden. www.sfv.se

[3] Törnquist, L., Svenska borgar och fästningar, Medströms, Stockholm, 2007. 